\title{
AUTONOMIA E DIREITO À INFORMAÇÃO: CONTRIBUIÇÕES PARA A GESTÃO DO CUIDADO DE IDOSOS HOSPITALIZADOS
}

\author{
AUTHONOMY AND RIGHT TO INFORMATION: CONTRIBUTIONS FOR \\ THE ELDER INMATE CARE MANAGEMENT
}

\section{AUTONOMÍA Y DERECHO A LA INFORMACIÓN: CONTRIBUCIONES PARA LA GESTIÓN DEL CUIDADO DE ANCIANOS HOSPITALIZADOS}

\author{
Viviani Camboin Meireles* \\ Laura Misue Matsuda \\ Jorseli Ângela Henriques CoImbra** \\ ÂNgela Maria Alvarez ${ }^{* * * *}$
}

\begin{abstract}
RESUMO
Estudo do tipo exploratório-descritivo que teve como objetivo verificar se os profissionais de enfermagem respeitam o direito à informação e o exercício da autonomia dos idosos hospitalizados, previstos em lei. Participaram 24 idosos de um município do interior do Estado do Paraná - Brasil, que responderam a um questionário, no domicílio, após a alta hospitalar. Dentre os resultados, obteve-se que 17 (70,8\%) desconheciam os seus direitos; 10 (41,7\%) não receberam informações sobre as normas e rotinas da instituição; para 12 (50\%) as dúvidas referentes à sua doença e evolução não foram esclarecidas; 13 (54,3\%) não foram informados sobre os cuidados recebidos; 17 (70,8\%) afirmaram que gostariam de participar das decisões sobre o seu cuidado, mas para $21(87,5 \%)$ essa conduta não foi possibilitada pela enfermagem. Quanto às informações/orientações sobre cuidados após a alta hospitalar, $10(41,7 \%)$ não foram orientados a respeito, $10(41,7 \%)$ receberam informações da equipe médica e somente $2(8,3 \%)$ receberam da enfermagem. Conclui-se que, nas instituições onde os sujeitos deste estudo estiveram internados, há necessidade de a enfermagem cumprir a legislação que diz respeito ao fornecimento de informações e ao exercício da autonomia do idoso.
\end{abstract}

Palavras chave: Acesso à informação, direitos dos idosos, assistência a idosos, gestão de qualidade em saúde.

\begin{abstract}
An exploratory descriptive study which aimed at verifying if the nursing professionals pay the respect to the right to information and the authonomy exercise of elderly inmates, predicted by the Law. Twenty-four elderly people, from a city of Parana state, in Brazil, took part in the study. They answered to a questionnaire, at their domicile, after their discharge from hospital. Among the results we had: $17(70,8 \%)$ elderly did not know their rights; $10(41,7 \%)$ did not receive information about the institution rules and routines; $12(50 \%)$ did not get their doubts, related to the disease and their health situation evolution, cleared; 13 (54,3\%) were not informed about the received care; 17 (70,8\%), said they would like to take part on the decisions about their treatment, but for $21(87,5 \%)$ informed that such participation was not allowed by the nursing team. In relation to the care after the discharge from hospital, $10(41,7 \%)$ did not receive any information about it, $10(41,7 \%)$ received such

\footnotetext{
* Enfermeira. Professora do Departamento de Enfermagem da Universidade Estadual de Maringá. Brasil. E-mail: vcmeireles@ibest.com.br

** Enfermeira. Professora do Departamento de Enfermagem da Universidade Estadual de Maringá. Brasil. E-mail: lmisue@ terra.com.br

${ }^{* * *}$ Enfermeira. Professora do Departamento de Enfermagem da Universidade Estadual de Maringá. Brasil. E-mail: coimbra@ wnet.com.br

${ }^{* * * *}$ Enfermeira. Professora do Departamento de Enfermagem da Universidade Federal de Santa Catarina. Brasil. E-mail: alvarez@nfr.ufsc.br
} 
information from the physician team and only $2(8,3 \%)$ received it from the nursing team. In conclusion, at the institutions where this study's participants were interned, the nursing staff needs to act according to what the elderly Law lays down, on the sense of providing suitable and sufficient information, as well as promoting this group autonomy.

Key words: Access to information, aged rights, old age assistance, health quality management.

\section{RESUMEN}

Estudio de tipo exploratorio descriptivo que tuvo como objetivo verificar si los profesionales de enfermería promueven la autonomía y el derecho a la información de ancianos hospitalizados, previstos en la ley. Participaron 24 ancianos de una municipalidad del interior del Estado de Paraná, Brasil, que respondieron a un cuestionario, en domicilio, tras el alta hospitalar. De entre los resultados se obtuvo: $17(70,8 \%)$ ancianos desconocían sus derechos; 10 (41,7\%) no recibieron informaciones sobre las normas y rutinas de la institución; 12 (50\%) no tuvieron respuestas para sus dudas referentes a la enfermedad y a la evolución de su cuadro de salud; 13 (54,3\%) no fueron informados sobre los cuidados recibidos; 17 (70,8\%) comentaron que a ellos les gustaría participar de las decisiones sobre su tratamiento/cuidado y 21 (87,5\%) informaron que en ningún momento esa participación fue permitida por la enfermera. En cuanto a las informaciones sobre los cuidados tras el alta hospitalar, $10(41,7 \%)$ no recibieron ninguna información al respecto, $10(41,7 \%)$ recibieron informaciones del equipo médico y solamente $2(8,3 \%)$ se refirió a que ese procedimiento fue realizado por algún miembro del equipo de enfermería. En conclusión, en las instituciones donde los participantes de este estudio fueron hospitalizados, el personal de enfermería tiene que actuar de acuerdo con lo que la ley establece, en el sentido de proporcionar información, así como promover el ejercicio de la autonomía de las personas ancianas.

Palabras clave: Acceso a la información, derecho de los ancianos, asistencia a los ancianos, gestión de calidad en salud.

Fecha recepción: 06/04/09 Fecha aceptación: 23/06/10

\section{INTRODUÇÃO}

$\mathrm{Na}$ atualidade, desenvolvem-se amplas discussões a respeito do exercício da autonomia do cliente/usuário/paciente. Como indivíduo autônomo se considera aquele que tem nele mesmo a fonte de decisão e, independente da faixa etária, escolhe e toma decisões livremente, sobre as alternativas que lhe são apresentadas (1).

$\mathrm{Na}$ área de saúde, à importância de se saber sobre as informações fornecidas pela equipe de enfermagem a idosos hospitalizados está relacionada ao respeito à autonomia do paciente e para exercê-la é fundamental que ele esteja bem informado sobre o seu estado de saúde, patologia, exames e procedimentos a que será submetido, além das normas e ro- tinas da instituição. As informações sobre esses aspectos, certamente instrumentalizam o cliente para fazer escolhas e exercer a sua autonomia (2).

No Brasil, a enfermagem garante os direitos tanto dos profissionais como dos usuários dos serviços, por meio de códigos de regulamentação ética (3) que reúnem normas e princípios, direitos e deveres dos profissionais, que devem ser adotados no atendimento à saúde da população.

No documento antes referido consta que todo cliente hospitalizado tem direito a atendimento atencioso e respeitoso; ser identificado pelo nome; ter as suas necessidades básicas atendidas; receber informações claras sobre o seu diagnóstico, tratamento e prognóstico em linguagem acessível; recusar tratamento e ser informado sobre as conse- 
qüências dessa opção e também, de reclamar daquilo que discorde, sem que a qualidade do seu tratamento seja alterada (2).

No que tange aos direitos dos idosos, além daqueles mencionados, o Estatuto do Idoso (4) garante à essa clientela o acesso universal e igualitário em todos os níveis de atenção à saúde; presença de acompanhante durante a hospitalização; atenção especial às doenças prevalentes nessa faixa etária e, enquanto tiver domínio das suas faculdades mentais, é assegurado o direito de optar pelo tratamento à sua saúde.

Para a Organização das Nações Unidas (ONU) (5) o conceito Idoso difere entre países desenvolvidos e em desenvolvimento, pois no primeiro, são consideradas idosas, as pessoas com 65 anos ou mais enquanto que, nos países em desenvolvimento, como é o caso do Brasil, a idade estabelecida como idoso é de 60 anos ou mais.

A compreensão das características dos idosos durante a internação hospitalar é importante porque facilita a identificação correta de seus problemas e a proposição de formas de atendimento diferenciadas que permitam melhor atendê-los (6). Desse modo, o conhecimento de como ocorre o processo de comunicação entre ele (idoso) e os profissionais certamente contribuem para que a enfermagem atue de maneira mais eficaz no planejamento, na organização e no alcance da qualidade do seu serviço.

Mediante a problemática apresentada e pelo interesse em viabilizar ações voltadas ao cumprimento dos direitos dos idosos estabelecidos legalmente no Brasil, especialmente àqueles hospitalizados, pergunta-se: Os profissionais da enfermagem cumprem a legislação pertinente ao idoso? Para responder a essa questão, se propõe a realização deste estudo que tem como objetivo verificar se os profissionais de enfermagem respeitam o direito à informação e ao exercício da autonomia de idosos hospitalizados, previstos em lei.

\section{MATERIAL E MÉTODO}

Estudo do tipo exploratório-descritivo de abordagem quantitativa dos dados, realizado com uma amostra de 24 idosos, que estiveram internados em dois hospitais públicos do Noroeste do Estado do Paraná - Brasil. A coleta de dados foi realizada no domicílio, no período de fevereiro a abril de 2006.

Como critérios de inclusão para participar do estudo estabeleceram-se: alta hospitalar do idoso no período de no máximo quinze dias até da data da entrevista; possuir idade igual ou superior a 60 anos; capacidade de comunicação (verbal ou escrita); tempo de internação de no mínimo quatro dias; residir na zona urbana do município em que o estudo se realizou e estar orientado no tempo e no espaço. $\mathrm{O}$ último critério foi conferido através de perguntas feitas pela pesquisadora, cujas respostas constavam no prontuário.

Inicialmente o acesso aos idosos ocorreu nos hospitais onde foi realizada consulta aos prontuários da Clínica Médica, para verificar a presença de clientes com idade igual ou acima de 60 anos. Sempre que as características do idoso atendessem aos critérios estabelecidos, este era informado sobre o objetivo, método de coleta de dados e implicações éticas do estudo. Mediante o consentimento verbal em participar do estudo, o seu endereço e outros meios de contato para agendamento da entrevista eram viabilizados.

Para a constituição da amostra, foram consultados 99 prontuários, porém 72 não atenderam aos critérios de seleção, resultando em uma amostra de 24 sujeitos.

A coleta de dados ocorreu nos primeiros quinze dias pós-alta, por ser considerado o período recordativo da doença, dos contatos com os serviços e também, por haver menos perda de informações devido a falhas de memória (7).

Destaca-se que o Projeto de Pesquisa referente a este estudo foi analisado e apro- 
vado pelo Comitê Permanente de Ética em Pesquisas com Seres Humanos (COPEP), da Universidade Estadual de Maringá, sob CAAE no 0236.0.093.000-05 e a assinatura do Termo de Consentimento Livre e Esclarecido (TCLE) pelo idoso ou seu representante, conforme está estabelecido em lei (8) foi condição essencial à participação no estudo.

$\mathrm{O}$ instrumento de coleta de dados se constituiu de um Questionário, com duas partes, elaborado para fins deste estudo, denominado "O Atendimento da Enfermagem ao Cliente Idoso Sob a Ótica dos Direitos Instituídos". Nesse instrumento, a primeira parte, denominada Dados Pessoais, buscou informações sobre as condições sócio-demográficas dos entrevistados e a segunda parte, intitulada Legislação e Direitos do Paciente Idoso, foi composta por questões referentes ao direito à informação e exercício da autonomia.

O referencial teórico de base à elaboração do instrumento de coleta de dados (Questionário) foi o Código de Ética dos Profissionais de Enfermagem (no que diz respeito aos deveres dos profissionais de Enfermagem) (3), a Carta dos Direitos do Paciente (2) e, o Estatuto do Idoso (4). Após a sua elaboração, o Questionário foi submetido à validade de aparência por sete juízes que eram enfermeiros e docentes, com título de Doutor, que atuavam na área da assistência/ pesquisa, ao idoso.

Após a realização das entrevistas, os dados foram agrupados e contabilizados por freqüência e porcentagens simples e a discussão, foi efetuada com base em publicações de autores que abordam o tema, associada à legislação vigente. Para ilustrar a discussão dos dados, alguns trechos de falas dos entrevistados, identificados com a letra $\mathrm{H}$ (para homens) e M (para mulheres), acompanhados de números de 1 a 24 , serão apresentados. As referidas falas foram adaptadas gramaticalmente à língua portuguesa, sem que se modificasse o conteúdo das mesmas.

\section{RESULTADOS E DISCUSSÃO}

Dentre os 24 entrevistados, $16(66,7 \%)$ eram do sexo feminino e oito $(33,3 \%)$ eram do sexo masculino. Em relação à distribuição por idade, $11(45,8 \%)$ se enquadravam na faixa etária de 60 a 69 anos; oito $(33,3 \%)$ na de $70-79$ anos e cinco (20,9\%) tinham 80 ou mais anos de idade.

Quanto à escolaridade, observou-se que $13(54,1 \%)$ não sabiam ler e escrever; um $(4,2 \%)$ relatou saber ler e escrever, mas referiu nunca ter freqüentado a escola; nove $(37,5 \%)$ referiram ter a sua escolaridade interrompida no Ensino Fundamental e apenas um $(4,2 \%)$ afirmou ter completado o Ensino Médio. Em relação à renda familiar, um idoso $(4,2 \%)$ referiu menos de um salário mínimo; 12 (50\%) recebiam apenas um salário mínimo e dois $(8,3 \%)$ referiram receber seis ou mais salários mínimos.

No que tange à parte específica, no Tabela 1 , se dispõe os resultados referentes ao respeito pelos profissionais de enfermagem, acerca do "direito a informação" e "exercício da autonomia" dos clientes idosos pelos profissionais.

Observa-se no Tabela 1 que $17(70,8 \%)$ dos $24(100 \%)$ idosos não conhecem os direitos à saúde que lhes são legalmente assegurados (questão 1). Esse fato, sem dúvida, limita ainda mais as chances dessa clientela exigir os seus direitos porque, com a falta de informação a respeito, eles podem perceber a atenção recebida como um favor e se tornarem resignados e incapazes de reclamar ou exigir por melhor atendimento. É fundamental então que os idosos tenham conhecimento dos seus direitos e benefícios à assistência à sua saúde, para que se organizem social e politicamente por meio de entidades da Terceira Idade e outros, para a efetivação do exercício da cidadania (9).

À outra questão, relacionada ao recebimento de informações acerca das normas e rotinas da instituição durante o período 
Tabela 1. Distribuição das respostas em relação às informações e ao exercício da autonomia, oportunizadas por profissionais de enfermagem aos idosos. Maringá - PR, 2006.

\begin{tabular}{|c|c|c|c|c|c|c|}
\hline Variável & \multicolumn{2}{|c|}{ Sim } & \multicolumn{2}{|c|}{ Não } & \multicolumn{2}{|c|}{$\begin{array}{l}\text { Não sabe / } \\
\text { Não } \\
\text { respondeu }\end{array}$} \\
\hline $\begin{array}{l}\text { 1. O Sr. (a) conhece os direitos à saúde do idoso assegurando por } \\
\text { lei? }\end{array}$ & & 29,2 & 17 & 70,8 & & - \\
\hline $\begin{array}{l}\text { 2. O Sr. (a) recebeu informações a respeito das normas e rotinas } \\
\text { do hospital durante a internação? }\end{array}$ & 14 & 58,3 & 10 & 41,7 & & - \\
\hline $\begin{array}{l}\text { 3. A enfermagem permitiu que o(a) } \operatorname{Sr} \text { (a) fizesse perguntas para } \\
\text { esclarecer dúvidas sobre a sua doença e tratamento? }\end{array}$ & 12 & 50,0 & 12 & 50,0 & & - \\
\hline $\begin{array}{l}\text { 4. O(a) Sr.(a) recebeu informações sobre os procedimentos que } \\
\text { lhe foram realizados? }\end{array}$ & 13 & 54,2 & 11 & 45,8 & & - \\
\hline $\begin{array}{l}\text { 5. O(a) Sr.(a) recebeu informações sobre os medicamentos que } \\
\text { lhe foram administrados? }\end{array}$ & 17 & 70,8 & 7 & 29,2 & & - \\
\hline $\begin{array}{l}\text { 6. A enfermagem permitiu que o(a) } \mathrm{Sr}(\mathrm{a}) \text { participasse das decisões } \\
\text { sobre os cuidados, tratamento e seu bem-estar? }\end{array}$ & 3 & 12,5 & 21 & 87,5 & & - \\
\hline $\begin{array}{l}\text { 7. O senhor (a) gostaria de participar das decisões sobre o seu } \\
\text { tratamento/cuidado? }\end{array}$ & 17 & 70,8 & 5 & 20,9 & 2 & 8,3 \\
\hline $\begin{array}{l}\text { 8. O (a) Sr.(a) recebeu orientações/informações sobre os cuidados } \\
\text { após a alta? Através de qual foi o profissional? }\end{array}$ & 14 & 58,3 & 10 & 41,7 & & - \\
\hline
\end{tabular}

da internação (questão 2), 14 (58,3\%) entrevistados responderam "Sim", $10(41,7 \%)$ responderam "Não". Apesar de a maioria ter recebido informações, estas parecem ser insuficientes porque, de acordo com alguns idosos, elas se limitavam ao horário do banho, da alimentação e da troca de acompanhante. Esses dados apontam que a informação ao idoso está sendo negligenciada e isso, aumenta os riscos à sua saúde porque o conhecimento detalhado das normas e rotinas do serviço onde o paciente está internado é fundamental para se sentir seguro, capaz de fazer escolhas e exercer sua autonomia (1).

Vale comentar a percepção de 10 idosos que referiram não precisar de informações sobre as normas e rotinas do hospital porque já tinham sido internados anteriromente no mesmo serviço. A conduta dos profissionais de não fornecer informações a cada nova internação é outro fator que potencializa os riscos porque tanto a rotina dos diversos serviços e os cuidados prestados pela enfermagem, são processos dinâmicos, passíveis de modificações freqüentes e, por isso, necessitam ser reapresentados pelos profissionais, ao cliente e seus familiares a cada internação.

Sabe-se que durante o período de hospitalização, o cliente necessita se adaptar ao sistema da instituição e em sendo assim, as regras e protocolos que disciplinam o comportamento das pessoas faz com que a enfermagem, para facilitar o seu trabalho, adote condutas que "robotizam" à sua forma de atuar (10). Para minimizar esse quadro, sugere-se que os trabalhadores da enfermagem, se atentem para uma atuação permeada na sensibilidade, nas preferências e nos fatores sócio-culturais de cada cliente.

A questão 3 procurou saber se a enferma- 
gem permitiu que o idoso fizesse perguntas para esclarecer as suas dúvidas sobre a doença e evolução do seu quadro de saúde. Dentre os $24(100 \%)$ idosos que responderam a essa questão, 12 (50\%) afirmaram ter recebido todas as informações que necessitavam e 12 (50\%), referiram que não.

O fornecimento de informações no ambiente hospitalar é pauta de discussões e também de discórdia entre os membros da equipe de saúde, porque apesar de a legislação (3) garantir esse direito ao cliente, em muitas instituições, somente ao profissional médico é permitido fornecer informações acerca do diagnóstico, da terapêutica e da evolução do paciente. Considera-se que, ainda que seja de forma breve, com parcimônia e sempre respeitando as obrigações e deveres de cada categoria profissional, previstos no Código de Ética, à enfermagem por estar presente nas 24 horas do dia junto ao cliente e freqüentemente de familiares, pode e deve fornecer informações sempre que for solicitada.

Ainda com relação a questão 3, oito $(33,3 \%)$ sujeitos justificaram as suas respostas e referiram que ao questionar sobre algo relacionado à sua doença e/ou tratamento, a resposta sempre era de que as perguntas deveriam ser direcionadas ao médico. Essa conduta, que também foi constatada em outros estudos $(11,12)$ necessita ser repensada porque, além de gerar angústias e riscos ao paciente e à sua família, caracteriza falta de compromisso e de respeito para com eles.

Os relatos a seguir sinalizam como os idosos são ignorados quando solicitam informações à enfermagem:

[...] se as enfermeiras sabiam, elas falavam. Se não sabiam ou não podiam falar, pediam para perguntar para o médico. (M3).

[...] a gente perguntava quanto era a pressão, elas não respondiam. Perguntava quanto estava o diabete, não respondia e pedia para perguntar ao médico. [...] muitas vezes faziam de conta que não ouviam a gente perguntar (M15).
Com base nas falas, percebe-se que as informações a serem fornecidas pela enfermagem são simples e não demandam tempo e nem esforços extras. Desse modo, a impressão que se tem é a de que a enfermagem tem "preguiça" de responder aos questionamentos ou considera que os "pacientes" devem assumir essa condição, no sentido léxico do termo.

Os resultados de um estudo sobre a percepção de clientes de um Hospital Universitário acerca do des (respeito) aos seus direitos no atendimento à saúde, constatou dados semelhantes, pois foi detectado que as informações fornecidas à clientela não correspondiam às suas necessidades. Os autores do referido estudo comentam que a equipe de saúde não fornecia informações e também não solicitava a opinião dos clientes pelo receio de que estes se tornassem questionadores, assumissem papel ativo no processo de atendimento e com isso, passassem a reivindicar a autonomia do seu corpo (12).

No documento que regulamenta a profissão da enfermagem no Brasil (3), consta que é dever do profissional contribuir com a equipe de saúde no esclarecimento das dúvidas do cliente e da família sobre o estado de saúde daquele, tratamento, possíveis benefícios e riscos. Em assim sendo, observa-se que há incompatibilidade entre a ética e a atuação do profissional porque a informação, que é o principal meio para que o indivíduo compreenda e decida sobre o seu tratamento, não é viabilizada.

Corroborando com a afirmação anterior, ao investigar a percepção das enfermeiras quanto ao respeito aos direitos dos clientes (13), foram identificadas quatro dimensões (informação para a tomada de decisão; respeito à autonomia; identificação pessoal e preservação da individualidade) e dentre elas, aquela relacionada à informação do cliente para a tomada de decisão era a menos realizada pelas enfermeiras.

No contexto do gerenciamento do cuidado, uma vez que a comunicação é ins- 
trumento básico da enfermagem e parte do processo cuidar, para que haja integração das informações para o planejamento e gerenciamento da assistência com qualidade, ela (a comunicação), necessita ser democratizada e largamente utilizada em todos os níveis (14).

A comunicação inadequada entre a equipe de enfermagem e os pacientes pode prejudicar o trabalho do grupo em virtude da falta do estabelecimento de uma relação de confiança entre eles, comprometendo o cuidado ao indivíduo e a sua recuperação. Com isso, para que o cuidado seja o mais efetivo possível, é preciso que na relação equipe de saúde-cliente, o medo e as preocupações sejam sempre minimizadas (15).

Questionou-se também se o idoso recebeu informações sobre os procedimentos que lhe foram realizados durante a hospitalização (questão 4) e como respostas obtiveram-se que a maioria, $13(54,2 \%)$, referiu que não foi comunicada a respeito e $11(45,8 \%)$, relataram que só foram informados sobre o nome do procedimento. Apesar de este ser um dado alarmante, estudo anteriormente citado (12), alcançou dados ainda mais elevados. No referido estudo, $68 \%$ dos entrevistados (clientes) responderam que não foram consultados ou informados sobre os procedimentos a que foram submetidos.

Como complemento das respostas da questão anterior, $13(54,2 \%)$ idosos mencionaram que apesar de sentirem necessidade de obter mais informações sobre a rotina do hospital, sobre a sua doença e tratamento, não fizeram nenhum questionamento à equipe por medo de "ofender" e/ou "irritar" os profissionais, evitando assim possíveis represálias.

Outra questão que tinha a ver com o fornecimento de informações, era a questão 5, relacionada aos medicamentos administrados pela equipe de enfermagem e que obteve as seguintes respostas: sete $(29,2 \%)$ referiram não ter recebido nenhum tipo de informação a respeito e $17(70,8 \%)$ afirmaram ter recebido. Dentre as informações recebidas, a maioria se baseava na comunicação sobre a forma ou tipo do medicamento como: uma "injeçãozinha" ou um "comprimidinho". Algumas vezes, os profissionais associavam o medicamento a algum sintoma do idoso, sem lhe dizer o tipo de droga; a indicação; possíveis efeitos colaterais e respectivos cuidados, conforme se vê nos relatos a seguir:

[...] não, a enfermeira ou o enfermeiro chegava lá e falava: é na barriga, e "tchok"! Faziam a injeção $[\ldots]$

Elas nunca explicaram. Eu também nunca perguntei. É capaz delas não gostarem [...] (M1).

[...] eles só falavam que o remedinho era para pressão, para diabete, para o coração [...] (H3).

Com base nos relatos, as informações a respeito da administração de medicamentos aos idosos, são breves e insuficientes. Essa situação, certamente ocorre porque os idosos não questionam os profissionais a respeito $\mathrm{e}$ também porque, têm receio de serem repreendidos e sofrerem retaliações.

A questão 6 buscou saber se a enfermagem em algum momento permitiu que os idosos exercessem a sua autonomia, ou seja, participassem das decisões sobre os cuidados sobre o seu tratamento e bem-estar. De acordo com $21(87,5 \%)$ entrevistados, em nenhum momento essa prática foi possibilitada. Conforme relato de alguns pacientes, os profissionais chegavam, executavam as atividades/ técnicas e, em seguida saiam sem nada dizer. Apenas três (12,5\%) tiveram oportunidade de fazer escolhas do tipo local para a aplicação de injeções, posição no leito e preferência do braço para instalação do soro. Aqui, mais uma vez, se percebe que a oportunidade de escolha pelo idoso é tímida e quando acontece, a situação envolvida é simples e de pouco impacto no processo de cuidado.

Questionou-se também se os idosos gostariam de participar das decisões sobre o 
seu tratamento. A essa questão 17 (70,8\%) responderam sim; cinco $(20,9 \%)$ responderam não e dois $(8,3 \%)$ afirmaram não ter opinião a respeito. Apesar de mais de $20 \%$ dos sujeitos não desejarem exercer o poder de decisão sobre o tratamento à sua saúde, a maioria $(70,8 \%)$ referiu que gostariam. Considera-se que a decisão do cliente junto com a equipe, dentro das suas possibilidades, permite àquele o exercício da sua cidadania, tornando-o co-participe e responsável pelo seu tratamento.

A participação do cliente nas decisões sobre o seu cuidado/tratamento é interessante e necessária, porque isso faz com que ele se torne parceiro da equipe de saúde "[...] sujeito participante do seu auto-cuidado, responsável por si, com capacidade de decidir e de exercer a sua liberdade" (12).

Sabe-se que à enfermagem cabe respeitar o direito do cliente em decidir sobre a sua pessoa, seu tratamento e seu bem-estar através da orientação e obtenção de consentimento ou recusa dos procedimentos diagnósticos ou terapêuticos a serem realizados. No âmbito do idoso, de maneira semelhante, se tiver domínio das suas faculdades mentais, ele também tem o direito de optar pelo tratamento de saúde que lhe julgar mais favorável $(2,3,4)$.

No cotidiano hospitalar se observa que a prática da escolha é limitada, principalmente porque o hábito da dependência é ainda muito incutido nos clientes e, em se tratando de idosos, essa concepção é ainda mais evidente. Enquanto a oportunidade para o auto cuidado e a tomada de decisão ocorre com maior freqüência nos pacientes adultos, com os idosos na mesma situação, essa prática comumente não ocorre (16).

A respeito do recebimento de informações durante a internação e alta hospitalar, para a continuidade do cuidado no domicilio, (questão 8), os resultados foram estes: $14(58,3 \%)$ responderam "Sim" e $10(41,7 \%)$ "Não". Sobre quem forneceu as orientações, $10(41,7 \%)$ relataram que a equipe médica; dois respectivamente mencionaram a enfermagem e a psicóloga e, 10 (41,7\%) informaram não ter recebido de nenhum profissional.

Os dados anteriores correspondem com a literatura que revela que é a equipe médica e outros profissionais da saúde, e não os da enfermagem, que fornecem a maioria das informações sobre a alta aos clientes. Outro agravante é que quando as informações são viabilizadas pela enfermagem, muitas vezes, elas se limitam à comunicação da alta à família e a saída do cliente da instituição (17).

Dentre as orientações fornecidas aos idosos deste estudo, as mais freqüentes se relacionavam aos medicamentos, à alimentação e às atividades físicas que, de acordo com os idosos, eram raras e superficiais. Mediante esses dados, considera-se que a enfermagem, por permanecer o tempo integral junto ao cliente e por ser o principal elo entre este e a equipe de saúde, necessita melhorar a forma e o conteúdo da sua comunicação.

Considera-se que as orientações fornecidas aos idosos entrevistados, não correspondem às suas necessidades e isso precisa ser melhorado porque, as orientações para a alta devem ser planejadas de acordo com as condições que cada cliente dispõe, associadas às suas necessidades pessoais.

De acordo com os resultados deste estudo, observa-se que nas instituições cujos idosos estiveram internados, o direito à informação e à autonomia não é respeitado pela maioria dos profissionais da enfermagem. Isso pode ser decorrência da falta de conhecimento da legislação que protege o idoso no Brasil, associada à condição de subalternidade, atribuída ao usuário do sistema de saúde.

\section{CONCLUSÃO}

Para cuidar de idosos o profissional deve ser capaz de estabelecer uma relação de cumplicidade e tratá-lo com dignidade e respeito, 
valorizando a sua história, as suas crenças, valores e necessidades.

A hospitalização, muitas vezes, é vivenciada pelos clientes, em especial pelos idosos, como uma condição de passividade e impotência, com comprometimento do seu processo decisório autonômico.

Com base nos dados deste estudo, recomenda-se aos profissionais da saúde e em especial aos da enfermagem que:

- Conheçam o conteúdo do código de ética dos profissionais de enfermagem e considerem prioritário informar, dialogar, orientar o cliente e a sua família;

- Favoreçam as ações de aprendizagem adaptadas a cada cliente/idoso em questões como: respeitar o seu ritmo, adotar um vocabulário simples, repetir intencionalmente as orientações, verificar o nível de compreensão do idoso e familiar e permitir sua participação no planejamento e na realização do cuidado;

- Prestem cuidados ao idoso e à sua família dando-lhes a oportunidade para falar de seus medos; angústias; sentimentos e desejos sem que se sintam ameaçados;

- Tenham menos preocupação com o cumprimento de tarefas e maior disponibilidade para ouvir o idoso e atender, na medida do possível, as suas vontades e necessidades.

Conclui-se que nas instituições hospitalares do município onde este estudo se realizou, os direitos dos idosos, relacionados à informação e à autonomia, não são respeitados de maneira sistemática pela equipe de enfermagem. Nesse contexto, o enfermeiro, enquanto gestor da sua equipe e da unidade/setor onde atua, deve promover diferentes meios que favorecem a comunicação e a difusão de informações à efetivação do exercício da cidadania e da autonomia dessa clientela.

\section{REFERENCIAS}

1. Paschoal SMP. Autonomia e independência. En: Papaléo Netto, M. Gerontologia: a velhice e o envelhecimento em visão globalizada. São Paulo: Atheneu; 2005. Pp. 312-23.

2. Direitos do paciente. O mundo da Saúde. 1995; 19 (10): 347-49.

3. Conselho Federal de Enfermagem. Resolução COFEN 240/2000. Aprova o código de ética dos profissionais de enfermagem e dá outras providências. Rio de Janeiro; 2000. Hallado em http://www.portalcofen.gov.br. Acesso em 5 abril 2009.

4. Brasil, Lei n. 10741 de $1^{\circ}$ de outubro de 2003. Dispõe sobre o estatuto do idoso e dá outras providências. Capítulo 4: do Direito à Saúde. Hallado em http://www. direitodoidoso.com.br. Acesso 9 junho 2009.

5. Organização das Nações Unidas. Assembléia mundial sobre envelhecimento: resolução 39/125. Viena; 1982.

6. Duarte YAO, Lebrão ML. O cuidado gerontológico: um repensar sobre a assistência em gerontologia. O Mundo da Saúde. 2005; 19(4): 566-574.

7. Cartwright A. Health surveys in practiceand in potential: a critical review of their scope methods. London: King Edward's Hospital Fund for London; 1983.

8. Ministério da Saúde (BR), Conselho Nacional da Saúde, Comitê Nacional de Ética em Pesquisa com Seres Humanos. Resolução 196 de 10 de outubro de 1996: diretrizes e normas regulamentadoras de pesquisas envolvendo seres humanos. Brasília (DF); 1997.

9. Duarte MJRS. Cuidando e educando o cliente idoso na perspectiva da cidadania. En: Saldanha AL, Caldas CP, organizadoras. Saúde do idoso: a arte de cuidar. Rio de Janeiro. $2^{\mathrm{a}}$ ed. Interciência; 2004. Pp. 59-73. 
10. Waldow VR. O cuidado na saúde as relações entre o eu, o outro e o cosmos. São Paulo: Loyola; 2004.

11. Chaves PL, Costa VT, Lunardi VL. A enfermagem frente aos direitos de pacientes hospitalizados. Texto contexto - enferm. 2005; 14(1): 38-43.

12. Santos LR, Beneri RL, Lunardi VL. Questões éticas no trabalho da equipe de saúde: o (des) respeito aos direitos do cliente. Rev Gaucha Enferm. 2005; 26(3): 403-13.

13. Alves PC, Lunardi-Filho VL, Lunardi GL, Lunardi-Filho WD. A percepção das enfermeiras acerca da sua atuação ante os direitos dos clientes. Rev. esc. enferm. USP. 2008; 42 (2):242-48.

14. Matsuda LM, Évora YDM. O método desdobramento da função qualidade -QFD- no planejamento do serviço de enfermagem. Cienc Cuid Saude. 2002; 1(1): 7174.

15. Silva MJP. O aprendizado da linguagem não-verbal e o cuidar. En: Stefanelli MC, Carvalho EC, organizadores. A comunicação nos diferentes contextos da enfermagem. São Paulo: Manole; 2005. Pp. 4761

16. Gandolpho MA, Ferrari MA. A enfermagem cuidando do idoso: reflexões bioéticas. O mundo da Saúde. 2006; 30(3): 398-408.

17. Pompeo DAL, Pinto MH, Cesarino $\mathrm{CB}$, Araújo RRDF, Poletti NAA. Atuação do enfermeiro na alta hospitalar: reflexões a partir dos relatos de pacientes. Acta paul. enferm. 2007; 20(3): 345-50. 